\title{
Early detection of cerebral ischemia due to pericardium traction using cerebral oximetry in pediatric minimally invasive cardiac surgery: a case report
}

Fumiaki Hayashi, Rei Nishimoto, Kazuyoshi Shimizu* (D), Tomoyuki Kanazawa, Tatsuo Iwasaki and Hiroshi Morimatsu

\begin{abstract}
Background: Minimally invasive cardiac surgery (MICS) for simple congenital heart defects has become popular, and monitoring of regional cerebral oxygen saturation $\left(\mathrm{rSO}_{2}\right)$ is crucial for preventing cerebral ischemia during pediatric MICS. We describe a pediatric case with a sudden decrease in $\mathrm{rSO}_{2}$ during MICS.

Case presentation: An 8-month-old male underwent minimally invasive ventricular septal defect closure. He developed a sudden decrease in $\mathrm{rSO}_{2}$ and right radial artery blood pressure (RRBP) without changes in other parameters following pericardium traction. The $\mathrm{rSO}_{2}$ and RRBP immediately recovered after removal of pericardium fixation. Obstruction of the right innominate artery secondary to the pericardium traction would have been responsible for it.

Conclusions: Pericardium traction, one of the common procedures during MICS, triggered $\mathrm{rSO}_{2}$ depression alerting us to the risk of cerebral ischemia. We should be aware that pericardium traction during MICS can lead to cerebral ischemia, which is preventable by cautious observation of the patient.
\end{abstract}

Keywords: Cerebral ischemia, Near-infrared spectroscopy, Pediatric, Minimally invasive cardiac surgery, Pericardium traction

\section{Background}

Over the last several decades, mortality following congenital heart surgery has been ameliorated because of innovative methodology and performance improvements in equipment used in cardiac surgery $[1,2]$. Thus, for better quality of life after congenital heart surgery, it is important to prevent brain dysfunction caused by cerebral ischemia following iatrogenic vessel obstruction during cardiac surgery with cardiopulmonary bypass (CPB). Recently, minimally invasive cardiac surgery (MICS), which is characterized by small skin incision and minimal sternotomy or minithoracotomy, has become popular for use with simple congenital heart surgery and has contributed to good outcomes [3-5]. However, a smaller incision used in MICS makes it more

\footnotetext{
* Correspondence: kshimizu@sb4.so-net.ne.jp

Department of Anesthesiology and Resuscitology, Okayama University Hospital, 2-5-1 Shikata-cho, Kita-ku, Okayama-shi, Okayama 700-8558, Japan
}

difficult to recognize vessel obstruction leading to cerebral ischemia. Therefore, adequate intraoperative monitoring of brain oxygenation is essential for preventing perioperative cerebral ischemia [6, 7]. Presently, monitoring of regional cerebral oxygen saturation $\left(\mathrm{rSO}_{2}\right)$ has assumed an important role in maintaining proper oxygenation of the brain during pediatric cardiac surgery $[6,7]$. Here, we report a pediatric case in which a sudden decline in $\mathrm{rSO}_{2}$ alerted us to the possibility of cerebral ischemia due to arterial malperfusion following pericardium traction.

\section{Case presentation}

The patient was an 8-month-old male (height $65.7 \mathrm{~cm}$; weight $7 \mathrm{~kg}$ ) born through normal vaginal delivery weighing $2768 \mathrm{~g}$. A heart murmur was audible, and the patient was diagnosed as having a perimembranous ventricular septal defect (VSD) with pulmonary hypertension due to a 
left-to-right shunt 4 days after birth. Transthoracic echocardiography (TTE) showed that the defect passed from the perimembranous septum to the infundibular septum. The defect was $7.4-8.9 \mathrm{~mm}$ in diameter and was accompanied by mild tricuspid regurgitation (TR) and mitral regurgitation. The peak TR pressure gradient was 54 $\mathrm{mmHg}$, and the left ventricle ejection fraction was $73 \%$. The patient had no other congenital heart malformations. Although the patient was administered diuretics after diagnosis, he had poor weight gain after 5 months of age, secondary to heart failure. Therefore, the patient was scheduled for VSD closure with lower partial sternotomy.

Preoperative data were within normal ranges, with the exception of the concentration of hemoglobin $(\mathrm{Hb})$ in blood ([Hb]) that was $10.2 \mathrm{~g} / \mathrm{dL}$. Upon arrival to the operating room, general anesthesia was induced with 5\% sevoflurane in a mixture of $50 \%$ nitrous oxide and 50\% oxygen. Following placement of an intravenous catheter, endotracheal intubation was facilitated with $70 \mu \mathrm{g}$ fentanyl and $10 \mathrm{mg}$ rocuronium. Anesthesia was maintained with $1-5 \%$ sevoflurane in the air, with concomitant fentanyl and rocuronium as required. During CPB, fentanyl, midazolam, and rocuronium were intravenously administered. Monitoring included electrocardiography and measurement of invasive right radial artery blood pressure (RRBP) and right femoral arterial blood pressure (RFBP), oxygen saturation of peripheral artery $\left(\mathrm{SpO}_{2}\right)$ in the patient's left finger and toe, end-tidal carbon dioxide $\left(\mathrm{E}_{\mathrm{T}} \mathrm{CO}_{2}\right)$, and central venous pressure $(\mathrm{CVP})$ via a central venous catheter inserted into the right internal jugular vein as well as nasopharyngeal and bladder temperatures. In addition to transesophageal echocardiography (TEE; iE33 xMATRIX S8-3 t Micro TEE transducer; Philips Japan, Ltd.), $\mathrm{rSO}_{2}$ was measured by using an INVOS 5100C (Medtronic Japan Co., Ltd.) adult sensor placed on the patient's right forehead. The insertion of the TEE probe did not affect the patient's vital signs. The patient's vital signs at the start of the operation were as follows: RRBP $82 / 44 \mathrm{mmHg}$, RFBP $91 / 52 \mathrm{mmHg}$, $\mathrm{SpO}_{2} 100 \%$ at fraction of inspired oxygen $\left(\mathrm{FiO}_{2}\right)$ 0.21, $\mathrm{E}_{\mathrm{T}} \mathrm{CO}_{2} 36 \mathrm{mmHg}, \mathrm{CVP} 10 \mathrm{mmHg}, \mathrm{rSO}_{2} 59 \%$, nasopharyngeal temperature $\left(\mathrm{T}_{\text {naso }}\right) 36.4{ }^{\circ} \mathrm{C}$, and $[\mathrm{Hb}] 10.2 \mathrm{~g} / \mathrm{dL}$.

Following lower partial sternotomy, the pericardium was towed cephalad and fixed to expose the aorta. Suddenly, RRBP decreased from $82 / 44$ to $26 / 22 \mathrm{mmHg}$, followed by a subsequent decrease in $\mathrm{rSO}_{2}$ from 59 to $16 \%$ (Fig. 1). Simultaneously, the other vital signs remained steady as follows: $\mathrm{RFBP} 88 / 44 \mathrm{mmHg}, \mathrm{SpO}_{2}$ $100 \%$ on the left hand $\left(\mathrm{FiO}_{2} 0.21\right), \mathrm{E}_{\mathrm{T}} \mathrm{CO}_{2} 36 \mathrm{mmHg}$, CVP $10 \mathrm{mmHg}$, and $\mathrm{T}_{\text {naso }} 36.3^{\circ} \mathrm{C}$. We confirmed that $[\mathrm{Hb}]$ was $10.2 \mathrm{~g} / \mathrm{dL}$ without any signs of sudden hemorrhage in the surgical area. On the basis of these parameters, the decreases of RRBP and $\mathrm{rSO}_{2}$ might have been caused by an obstruction of the right innominate

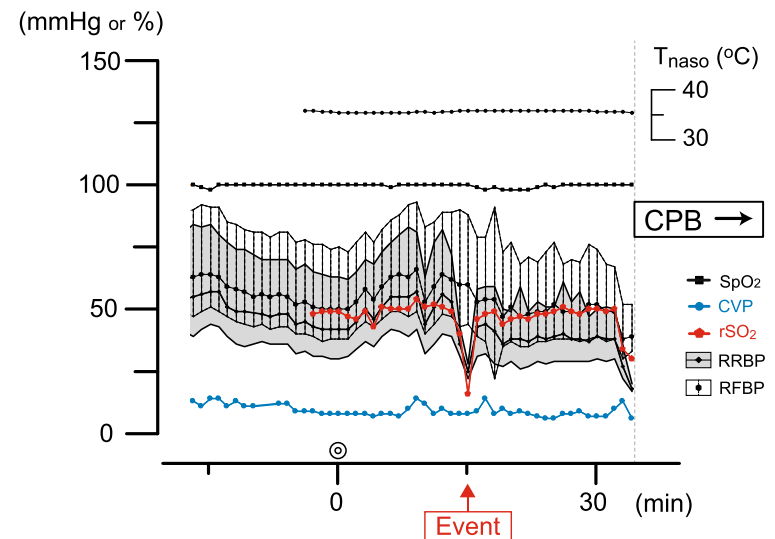

Fig. 1 Changes in parameters monitored during general anesthesia around the event of $\mathrm{rSO}_{2}$ depression. The graph represents changes of each parameters monitored every minute during general anesthesia from the beginning of the operation to the period just before initiation of cardiopulmonary bypass (CPB). The parameters are as follows: right radial blood pressure (RRBP), right femoral blood pressure (RFBP) and central venous pressure (CVP), oxygen saturation of peripheral artery $\left(\mathrm{SpO}_{2}\right)$, values of regional cerebral oxygen saturation $\left(\mathrm{rSO}_{2}\right)$ measured with INVOS 5100C, and nasopharyngeal temperature $\left(T_{\text {naso }}\right)$. Some of these points beyond measurement limits are considered noise and were thus excluded

artery, secondary to the pericardium and aortic root traction. We promptly discussed this issue with the surgeons and reached a consensus to remove the pericardium fixation. Following removal, RRBP increased to 59/ $33 \mathrm{mmHg}$ and $\mathrm{rSO}_{2}$ to $>50 \%$. Transient reduction in RRBP and $\mathrm{rSO}_{2}$ continued for approximately $30 \mathrm{~s}$ until the pericardial fixation was removed. Subsequently, the traction of pericardium was modified to maintain $\mathrm{rSO}_{2}$ stability. After modification, the operation proceeded uneventfully. Postoperatively, the patient was transferred to the intensive care unit (ICU) under sedation and intubated. The patient gained consciousness and was extubated $3 \mathrm{~h}$ later, without any neurological abnormalities. The patient was discharged from the ICU on postoperative day 3.

\section{Discussion}

In this case, pericardium traction, one of the common procedures during MICS, triggered a decrease in $\mathrm{rSO}_{2}$ that alerted us to the risk of cerebral ischemia. The change in $\mathrm{rSO}_{2}$ was sufficient to cause us to speculate that cerebral ischemia might have occurred in the patient.

Recently, a smaller incision during median sternotomy has become an alternative technique during cardiac surgeries for simple congenital heart deformities, such as closure of VSD and atrial septum defects $[3,5]$. The smaller incision in pediatric MICS forces the surgeon to pull up the pericardium more strongly to secure a field 

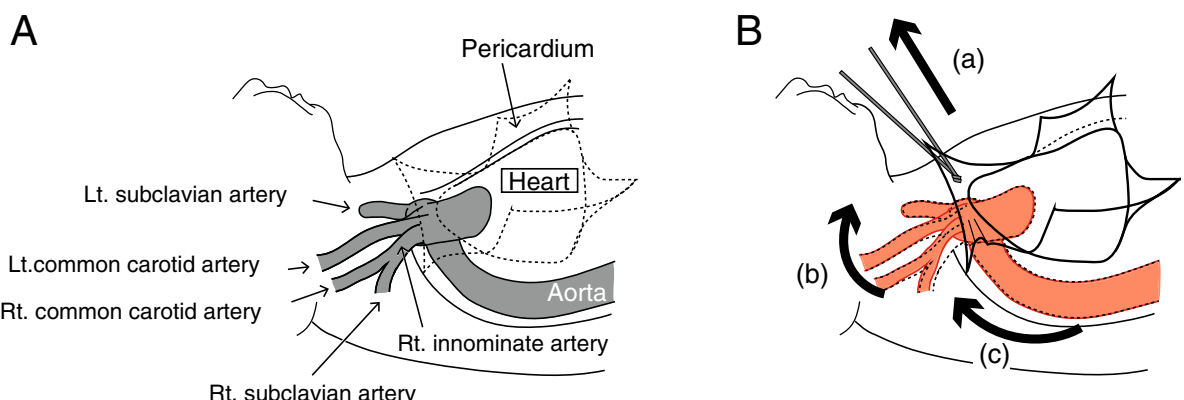

(a) Cephalad traction of pericardium

(b) Sliding up of pericardium

(c) Kinked rt. innominate artery

Fig. 2 Schematic of our hypothesis. Anatomical images of the aortic root and the pericardium (A) and obstruction of the right innominate artery by pericardium traction (B). Cephalad traction of the pericardium (a) moves the aortic root to the cephalad ventral direction (b) and obstructs the right innominate artery (c). Rt, right; Lt, left

of view, which can subsequently deform the aorta or the branch (Fig. 2B), which would possibly lead to cerebral ischemia. Additionally, it is extremely difficult to visualize such a physical deformity of arteries by TEE in pediatric MICS. Hence, monitoring of cerebral saturation by near-infrared spectroscopy (NIRS) is becoming an alternative for avoiding such an unforeseen emergency. Some groups have reported that the decrease in $\mathrm{rSO}_{2}$ was related to the surgical procedure in cardiac surgery $[8,9]$, whereas few reports have shown that simple traction of the pericardium can affect $\mathrm{rSO}_{2}$ values as we experienced.

Accumulating studies show that the $\mathrm{rSO}_{2}$ values measured by NIRS are trustworthy physiological indicators during pediatric cardiovascular surgeries $[6,7]$. An interventional algorithm to prevent cerebral desaturation using NIRS has been introduced as a feasible strategy in clinical situations $[7,10,11]$. Following that algorithm, we concluded that arterial malperfusion was plausible because of the following observations: (1) the RRBP and $\mathrm{rSO}_{2}$ values dropped simultaneously, (2) $\mathrm{SpO}_{2}$ on the left hand remained unchanged, (3) the RFBP was maintained, (4) there was no apparent hemorrhage, (5) the CVP did not change, and (6) the patient's heart rate and body temperature remained stable. Our decision to insert two artery catheters at the right radial artery and right femoral artery and monitor $\mathrm{SpO}_{2}$ at the left hand and foot may have been excessive. However, we aimed to monitor the blood flow at all the extremities during pediatric MICS in order to be alert to any signs indicating obstruction of blood flow. It ultimately gave us more clues to understand what happened in this emergent situation and for future reference.

There are limitations to the use of NIRS devices for monitoring of cerebral saturation. In the present case, we chose the INVOS sensor that reflects a mixture of $\mathrm{Hb}$ saturation in venous, capillary, and arterial blood [7].
Alternatively, $\mathrm{NIRO}^{\circ}$, another device for monitoring cerebral saturation, can give us detailed information from each source [12]. Another issue to be considered is that we used an adult sensor to measure the $\mathrm{rSO}_{2}$ value. Although standard values of $\mathrm{rSO}_{2}$ vary depending on the type of sensor used [13, 14], they are enough to be trustworthy $[6,7]$. In this case, we did not check bilateral brain saturation, but monitoring of RRBP and $\mathrm{SpO}_{2}$ on the left hand provided us enough information. A carotid artery ultrasound and/or Transcranial Doppler ultrasound may be preferable for detecting cerebral malperfusions.

In conclusion, we experienced a pediatric case of MICS in which pericardium traction, one of the common procedures in MICS, caused a decrease in $\mathrm{rSO}_{2}$, but we were able to prevent cerebral ischemia during the surgery with useful monitoring including $\mathrm{rSO}_{2}$, arterial blood pressure, and $\mathrm{SpO}_{2}$ at extremities. To achieve better quality of life after congenital heart surgery, we should be aware that pericardium traction during MICS can lead to cerebral ischemia that is preventable by cautious observation of the patient.

\section{Abbreviations \\ CVP: Central venous pressure; ECG: Electrocardiography; $\mathrm{E}_{\mathrm{T}} \mathrm{CO}_{2}$ : End-tidal carbon dioxide; $\mathrm{FiO}_{2}$ : Fraction of inspired oxygen; $\mathrm{Hb}$ : Hemoglobin; ICU: Intensive care unit; MICS: Minimally invasive cardiac surgery; NIRS: Near-infrared spectroscopy; RFBP: Right femoral arterial blood pressure; RRBP: Right radial arterial blood pressure; $\mathrm{rSO}_{2}$ : Regional cerebral oxygen saturation; $\mathrm{SpO}_{2}$ : Oxygen saturation of peripheral artery; $\mathrm{T}_{\text {naso: }}$ Nasopharyngeal temperature; TR: Tricuspid regurgitation; VSD: Ventricular septal defect}

\section{Acknowledgements}

None

\section{Authors' contributions}

FH drafted the article. RN helped with the critical revision of the article for important intellectual content. KS helped with the revision of the article. TK helped with the revision of the article. TI helped with the revision of the article. HM finally approved the article. All authors read and approved the final manuscript. 


\section{Funding}

The authors have no funding.

\section{Availability of data and materials Not applicable.}

Ethics approval and consent to participate

Ethics approval was waived because this manuscript is a case report

\section{Consent for publication}

Written informed consent was obtained from the patient's parent for the publication of this case report.

\section{Competing interests}

The authors declare that they have no competing interests.

Received: 7 June 2019 Accepted: 12 August 2019

Published online: 17 August 2019

\section{References}

1. Jacobs JP, He X, Mayer JE Jr, Austin EH 3rd, Quintessenza JA, Karl TR, et al. Mortality trends in pediatric and congenital heart surgery: an analysis of The Society of Thoracic Surgeons Congenital Heart Surgery database. Ann Thorac Surg. 2016:102:1345-52.

2. Hirata Y, Hirahara N, Murakami A, Motomura N, Miyata H, Takamoto S. Current status of cardiovascular surgery in Japan 2013 and 2014: a report based on the Japan Cardiovascular Surgery Database. 2: Congenital heart surgery. Gen Thorac Cardiovasc Surg. 2018;66:4-7.

3. Bichell DP, Geva T, Bacha EA, Mayer JE, Jonas RA, del Nido PJ. Minimal access approach for the repair of atrial septal defect: the initial 135 patients. Ann Thorac Surg. 2000;70:115-8.

4. Iribarne A, Easterwood R, Chan EY, Yang J, Soni L, Russo MJ, et al. The golden age of minimally invasive cardiothoracic surgery: current and future perspectives. Future Cardiol. 2011;7:333-4.

5. Vida $V L$, Zanotto $L$, Tessari $C$, Padalino $M A$, et al. Minimally invasive surgery for atrial septal defects: a 20-year experience at a single centre. Interact Cardiovasc Thorac Surg. 2019:28:961-7.

6. Dullenkopf A, Frey B, Baenziger O, Gerber A, Weiss M. Measurement of cerebral oxygenation state in anaesthetized children using the INVOS 5100 cerebral oximeter. Paediatr Anaesth. 2003;13:384-91.

7. Murkin JM, Arango M. Near-infrared spectroscopy as an index of brain and tissue oxygenation. Br J Anaesth. 2009;103 (Suppl. 1:i3-13.

8. Ito R, Takita K, Mizunoya K, Kida A, Morimoto Y. Use of near-infrared spectroscopy in combination with monitoring of external jugular vein pressure for early detection of cerebral ischemia by unintentional superior vena cava obstruction. J Cardiothorac Vasc Anesth. 2011;26:e27-8.

9. Rossi M, Tirotta CF, Lagueruela RG, Madril D. Diminished Blalock-Taussig shunt flow detected by cerebral oximetry. Paediatr Anaesth. 2007:17:72-4.

10. Denault A, Deschamps A, Murkin JM. A proposed algorithm for the intraoperative use of cerebral near-infrared spectroscopy. Cardiothorac Vasc Anesth. 2007;11:274-81.

11. Deschamps A, Hall R, Grocott H, Mazer CD, Choi PT, Turgeon AF, et al. Cerebral oximetry monitoring to maintain normal cerebral oxygen saturation during high-risk cardiac surgery. Anesthesiology. 2016;124:826-36.

12. Redlin M, Huebler M, Boettcher W, Kuppe $H$, Hetzer $R$, Habazettl $H$. How near-infrared spectroscopy differentiates between lower body ischemia due to arterial occlusion versus venous outflow obstruction. Ann Thorac Surg. 2011;91:1274-6.

13. Dix LM, Bel FV, Baerts W, Lemmers PM. Comparing near-infrared spectroscopy devices and their sensors for monitoring regional cerebral oxygen saturation in the neonate. Pediatric Res. 2013;74:557-63.

14. Yagi Y, Yamamoto M, Saito H, Mori T, Morimoto Y, Oyasu T, et al. Changes of cerebral oxygenation in sequential Glenn and Fontan procedures in the same children. Pediatr Cardiol. 2017:38:1215-9.

\section{Publisher's Note}

Springer Nature remains neutral with regard to jurisdictional claims in published maps and institutional affiliations.

\section{Submit your manuscript to a SpringerOpen ${ }^{\circ}$ journal and benefit from:}

- Convenient online submission

- Rigorous peer review

- Open access: articles freely available online

- High visibility within the field

Retaining the copyright to your article

Submit your next manuscript at $\boldsymbol{\nabla}$ springeropen.com 